\title{
A review of the effectiveness of the application of reality therapy in education in the last 5 years
}

\author{
$\mathrm{Au}$, Phuong Anh $\triangle$ \\ De La Salle University, Manila, Philippines (teresanho0612@gmail.com)
}

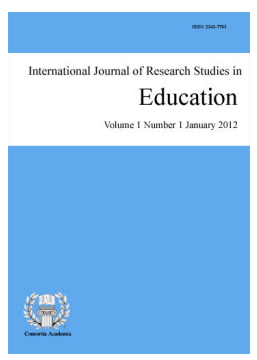

Accepted: 1 November 2021

ISSN: 2243-7703 Online ISSN: 2243-7711

OPEN ACCESS

\section{Abstract}

The findings of Reality Therapy interventions in education have an important impact on student's achievement and performance. Psychologists have tried to find out the approaches regarding assisting students to solve their problems in schools. The present study reviews the effectiveness of the application of Reality Therapy in education in the last 5 years. The researcher collects 16 studies of applying Reality Therapy in education from 2016 to 2020 and classifies them according to qualitative method (3), quantitative method (10), and mixed-method (3). Through documentary analysis, this research aims to answer the question of how the efficacy of applying Reality Therapy in education is described. The findings show that Reality Therapy has been applied with positive results in schools for problems related to reconstructing self-evaluation, pursuing efficient goals, and taking personal responsibility. The result of this study contributes to the prevailing knowledge which may be used as a reference for guidance and counseling services to assist students overcome their challenges.

Keywords: reality therapy, choice theory, basic needs, quality world, WDEP system 


\section{A review of the effectiveness of the application of reality therapy in education in the last 5 years}

\section{Introduction}

Students are among the most important groups of the society and influence the progression of the country. Meanwhile, they are usually faced with stressors that may cause health problems, low learning motivation, less confidence, low self-esteem. Thus, school counselors and counseling programs are relevant to any current society. Mason and Duba (2009) have suggested Reality Therapy techniques be employed to school counseling services because they believe that Reality Therapy practitioners have the potential to assist students effectively in terms of educational achievement, vocational direction, and spiritual growth.

Between the various ways, Reality therapy is known more than other approaches for working with students (Mason \& Duba, 2009). Reality therapy, developed by Dr. William Glasser in 1965, was based on Choice theory. This theory underscores five basic needs of man (survival, love and belonging, power, freedom, and fun). Hence, human beings are motivated to meet their needs by creating the "quality world" of them. This world includes the beloved ones, ideas, and desires (Odac1 \& Çelik, 2017; Vahidiborji et al., 2017; Zare \& Namdarpour, 2020). Reality therapy powerfully assists students identify their successful identity through the WDEP system, an interdependent set of skills, and depends on different circumstances (Hajhosseini, 2016; Shafie et al., 2019). This system includes helping students clarify their wants (W), describe what they are doing (D), evaluate their wants and behaviors (E), and create concrete plans so that students can achieve their goals (P) (Wubbolding et al., 2017).

Reality Therapy is considered as the newest psychotherapy approach which shows that psychological problems are caused by personal choices and responsibility (Çelik \& Odaci, 2018; Odacı \& Çelik, 2017; Sunawan \& Junmei, 2016; Vahidiborji et al., 2017; Zare \& Namdarpour, 2020). Hence, the application of Reality Therapy allows students to gain self-awareness, responsibility, and control behaviors and choices (Odacı \& Çelik, 2017; Vahidiborji et al., 2017; Zare \& Namdarpour, 2020). This therapy was proven to be effective in addressing various students' problems at schools (Sunawan \& Junmei, 2016; Shafie et al., 2019). Besides, Choice theory was also used as the key principles for understanding and developing students' efficient achievement goals (Nurjanah et al., 2020; Sunawan \& Junmei, 2016).

In advanced educational systems, self-awareness, responsibility, and control behaviors and choices are the most important applications of Reality therapy (Nurjanah et al., 2020; Vahidiborji et al., 2017). Thus, there is numerous studies of the effectiveness of applying Reality therapy in education over the decades. However, collecting and synthesizing data on those researches have not received much attention. How has been the efficacy of applying Reality therapy in school counseling described in the last 5 years? This literature will discuss the three main themes: reconstructing self-evaluation, pursuing efficient goals, and taking personal responsibility as the efficient application of Reality therapy in education from 2016 to 2020.

\subsection{Reconstructing self-evaluation in reality therapy}

The application of Reality therapy is widely known in school counseling as an efficient approach in reconstructing self-evaluation. Students who have experienced many failures in their achievement goals would be inspired with the Choice theory tenets in deciding their goals and strategies, responding and giving meaning to those goals so that they can properly accomplish academic achievement goals in better ways (Nurjanah et al., 2020; Sunawan \& Junmei, 2016). Reality therapy-based programs were also employed for dealing with internet dependence by helping students recognize their problematic behaviors as well as the negative impacts of the internet (Odacı \& Çelik, 2017; Shafie et al., 2019). Hence, they knew how to use their time more effectively to

12 Consortia Academia Publishing (A partner of Network of Professional Researchers and Educators) 
reach a better life. More concretely, Çelik and Odaci (2018) showed that students were aided to find out the fundamental concepts of Reality therapy and Choice theory and apply them to their own experiences (Vahidiborji et al., 2017; Zare \& Namdarpour, 2020). In doing so, they understood their problematic procrastination, then they had more effective control of their lives to require action to vary their behaviors (Odac1 \& Çelik, 2017; Shafie et al., 2019). From that point, their learning motivation was also improved by their responsibility (Nurjanah et al., 2020; Sunawan \& Junmei, 2016).

\subsection{Pursuing efficient achievement goals bases on the principles of reality therapy}

The key concepts of reality therapy are suited to the structure of academic motivation, and the basic principles of Reality therapy (choice, responsibility, basic needs, social behavior, WDEP system) were employed to develop coping skills for academic procrastination as well as enhance learning motivation (Celik \& Odaci, 2018; Nurjanah et al., 2020). Specifically, Reality therapy assists individuals in being aware of the situation, making decisions, and attempting to alter behavior. Therefore, Reality therapy are worth applying about helping students pursue effectively their goals (Nurjanah et al., 2020; Sunawan \& Junmei, 2016). In addition, Reality counseling enables students to adopt effective achievement goals that can be applied in daily learning activities. Briefly, using Reality therapy is valuable for strengthening students' learning motivation (Çelik \& Odaci, 2018; Mulawarman et al., 2017).

\subsection{Taking personal responsibility through choice theory training}

Choice theory trains the individuals to increase the responsibility rate for their behaviors. Particularly, Reality therapy-based group counselling was an efficient intervention in helping students realize unhealthy ways in spending time in using the internet as well as recognizing their responsibility for the physiological and psychological problems (Odacı \& Çelik, 2017; Shafie et al., 2019). Moreover, the relevant principles of Choice theory were employed as the interventions to extend the strength of internal control in students so that they can take responsibility for strengthening their spiritual health (Farnoodian, 2016; Vahidiborji et al., 2017; Zare \& Namdarpour, 2020). Zare and Namdarpour (2020) asserted that focusing on the prior needs and responsibility in Choice theory training could be useful in growing students' spiritual health. However, the longer term measurements (like 6 or 12 months) were not made to reveal how long the effects of the training program lasted.

\section{Methodology}

\subsection{Research question}

The purpose of the research as presented in this paper was to analyze key documents and discuss how the effectiveness of the application of Reality therapy in education is described in the last 5 years. Research question 1 was used as a basis to collect data:

1. What documentary evidence emerges in applying Reality therapy in education effectively?

and, research question 2 guided the analysis and interpretation:

2. How is the effectiveness of applying Reality therapy in education in the last 5 years described?

\subsection{Data collection}

A document analysis was used as the method for collecting and analyzing the effectiveness of the application of Reality therapy in education. Within the limit of a research paper required for the output of this course "Techniques of Counseling", the researcher collects 16 studies of applying Reality therapy in education from 2016 to 2020 and classifies them according to qualitative method (3), quantitative method (10), and mix-method (3). The researcher will organize the information from the documents into categories: positive 
results, method, and authors in chronological order.

A secondary analysis of these outcomes will be discussed in relation to the three considerations identified as the strengths of Reality Therapy applications: self-evaluation, personal responsibility, and planning for change to pursue achievement goals.

\section{Results and Discussion}

The following table shows that Reality therapy has been applied with positive results in schools regarding assisting students solve their problems:

\begin{tabular}{clll}
\hline & & Positive Results & Method \\
\hline 1 & Implement effective achievement goals & Qualitative & Sunawan \& Junmei (2016) \\
2 & Take personal responsibility & Qualitative & Mabeus (2016) \\
3 & Increase self-concept & Qualitative & Jusoh (2018) \\
4 & Promote the mental health and self-esteem & Quantitative & Farnoodian (2016) \\
5 & High positive influence on problem solving skills & Quantitative & Masoudi et al., (2016) \\
6 & Improve behavioral self-regulation & Quantitative & Hajhosseini et al. (2016) \\
7 & Reduce problematic internet use; increase life satisfaction & Quantitative & Odaci \& Çelik (2017) \\
8 & Increase adjustment & Quantitative & Vahidiborji et al. (2017) \\
9 & Decrease academic procrastination behavior & Quantitative & Çelik \& Odaci (2018) \\
10 & Increase interpersonal skills & Quantitative & Shafie et al. (2019) \\
11 & Promote the happiness and self-esteem & Quantitative & Fereydouni et al. (2019) \\
12 & Enhance learning motivation and discipline & Quantitative & Nurjanah et al. (2020) \\
13 & Increase the mental health & Quantitative & Zare \& Namdarpour (2020) \\
14 & Decrease self-motivation problems & Mix-method & Mulawarman et al., (2017) \\
15 & Increase the self-esteem & Mix method & Iswinarti \& Wahyuningsih (2018) \\
16 & Decrease bullying behavior & Mix-method & Sari et al. (2020) \\
\hline
\end{tabular}

The level of competence of a counselor can be assessed based on the ability to interpret a theory and turn that theory into practice. To successfully apply Choice theory, the counselor should understand clients' issues based on their own needs (Odacı \& Çelik, 2017; Vahidiborji et al., 2017), and know how to use Reality therapy based on the WDEP process (Mabeus, 2016; Farnoodian, 2016; Masoudi et al., 2016; Çelik \& Odaci,2018; Shafie et al., 2019). When employed implicitly, this method has the potential to effectively help clients achieve their original goals (Hajhosseini et al., 2016; Iswinarti \& Wahyuningsih, 2018; Shafie et al., 2019; Nurjanah et al., 2020).

\subsection{The effectiveness of applying Reality therapy is described through 3 qualitative studies}

It is essential for students to become more responsible and flexible in the context of learning with awareness of choices (Malone, 2002; as cited in Sunawan \& Jumei, 2016). Reality therapy is considered an effective approach to assist students in developing their awareness of learning motivation by assessing their negative behaviors (Nurjanah et al., 2020; Sunawan \& Junmei, 2016). Particularly, Sunawan and Junmei (2016) admitted that students in the three styles of intervention, who often fail in their academic subjects, need to be motivated by Choice Theory tenets to assist them take personal responsibilities and planning for pursuing effective achievement goals. Though this study only focuses on the efficacy of the intervention strategies and not yet oriented toward understanding the inner strengths during counseling, this application model is count on a new approach for school counselors when using Reality therapy to help students establish effective achievement goals in individual counseling process.

Choice theory concepts promote the students to take personal responsibility for future behaviors as the case of Rebecca (Mabeus, 2016). In general, students often see that their current behaviors are not bringing them what they want. From this point, Jusoh (2018) asserted that students' expectations of the others are external controls that can affect their choices in behaviors. Most students believed that family members, peers, teachers, the school's principles, and the classroom's atmosphere in somehow are the causes behind their struggles (Mabeus, 2016; Jusoh, 2018). However, they are only cause to symptoms. The main problems are rooted in the internal 
A review of the effectiveness of the application of reality therapy in education in the last 5 years

control. For example, insecure family backgrounds with limited support greatly contributed to students' misbehaviors (Jusoh, 2018; Mabeus, 2016). According to Danielle Mabeus, "the WDEP model serves as a tool to break down choices and pushes students to alter their individual perceptions" (Mabeus, 2016, p.51). Therefore, Reality therapy is a useful form of therapy for school counselors because it gives students the chance to take control of their choices and behaviors (Banks, 2009; as cited in Mabeus, 2016; Jusoh, 2018).

\subsection{The effectiveness of applying Reality therapy is described through 10 quantitative studies}

Choice theory and Reality therapy teach all participants the value and accountability of decision-making, and thus, is also important in the group counseling process (Celik \& Odaci, 2018; Farnoodian, 2016; Fereydouni et al., 2019; Hajhosseini et al., 2016; Jusoh, 2018; Nurjanah et al., 2020; Masoudi et al., 2016; Shafie et al., 2019; Vahidiborji et al., 2017; Zare \& Namdarpour, 2020). In these ten studies, the counselors employed the WDEP procedure to help students in a group setting. Those researchers found that students could change more when they felt comfortable with other participants and when there was a mutual self-disclosure within the group (Iswinarti \& Wahyuningsih, 2018; Mulawarman et al., 2017; Shafie et al., 2019; Zare \& Namdarpour, 2020). In general, group counseling provides an opportunity for the members to speak out the problems, and receive feedbacks.

Through the sharing in a group, the individuals can strengthen his/her interpersonal skills and have better relationships with the others (Farnoodian, 2016). In group Reality therapy sessions, the members are taught to effectively control, plan, and self-evaluate what they do. In doing so, students not only strengthen their self-evaluation skills, but also promote their affirmation of themselves as more positive self-concepts (Hajhosseini et al., 2016; Vahidiborji et al., 2017). Reality therapy-based group counseling assists students by encouraging them to be more responsible; increasing their perception of values as well as giving them the opportunity to learn more about appropriate behaviors and attitudes that can improved the mental health, happiness, self-esteem, life satisfaction, learning motivation, interpersonal skills, problem solving skills of students, even decrease their misbehaviors (Celik \& Odaci, 2018; Farnoodian, 2016; Fereydouni et al., 2019; Hajhosseini et al., 2016; Jusoh, 2018; Nurjanah et al., 2020; Masoudi et al., 2016; Shafie et al., 2019; Vahidiborji et al., 2017; Zare \& Namdarpour, 2020).

In fact, challenging unconstructive thoughts in group counseling will put forward building efficient goals, and strengthen self-efficacy. Odacı and Çelik (2017) demonstrated that Reality therapy-based group counseling helped participants recognize that they used the internet in an abusive manner. Since then, they were aware of their accountability for the physiological and psychological issues as consequences of spending hours online (Corey, 1996; Wubbolding, 2000; as cited in Odacı and Çelik, 2017). Thus, students gain both of awareness of self-control and responsibility to manage properly their time in light of their wants and basic requirements. Thereby, students would find out the levels of life satisfaction as a result of utilizing the internet in a right way (Odac1 and Çelik, 2017; Shafie et al., 2019). More concretely, Reality therapy helps the students deeply understand their strengths and weaknesses as well as the ability to evaluate and control their life situations (Vahidiborji et al., 2017; Zare \& Namdarpour, 2020). This ability has an indispensible role in developing of insights, promoting emotional regulation, and being a fully functional person (Fereydouni et al., 2019; Mulawarman et al., 2017; Shafie et al., 2019; Zare \& Namdarpour, 2020).

Beside identifying the cause of students' negative thoughts and actions, finding the source of learning motivation is also considered intentionally (Hanif, 2013; as cited in Nurjanah et al., 2020). In other words, the counselors might use the WDEP approach while doing reality counseling with students who have less motivation since this method was employed to help clients put forward their commitments (Fauziah \& Nursalim, 2013; as cited in Nurjanah et al., 2020). Especially, happiness and academic success were proven that they were strongly linked together through Reality therapy-based group counseling (Fereydouni et al., 2019). According to Zare and Namdarpour (2020), humans embrace their wants, hope, desires, ideas, thoughts and behaviors to gain the most satisfied condition for themselves. Since behavior was the result of human choice, Choice theory training 
strengthens the source of inner control and responsibility in individuals, causing them to hold themselves accountable for their physical and spiritual health (Fereydouni et al., 2019; Farnoodian, 2016; Zare \& Namdarpour, 2020).

\subsection{The effectiveness of applying Reality therapy is described through 3 mix-method studies}

The strength of this mix-method is that statistical analysis is used to identify the level of self-motivation problems while the clinical analysis is conducted to analyze students' speech and behaviors to find out the changing during counseling process (Mulawarman et al., 2017; Sari et al., 2020). For example, Mulawarman et al., (2017) demonstrated that Reality therapy was effective to reduce self-motivation problems. Through the intervention, researchers invited participants to assess their behaviors, desires, and academic tasks. In addition, interventions are also oriented to finding which choices that lead the subjects to more responsible performance. The conversation analysis results showed that the transformation appeared in students' speech and actions. Hence, the counselors have more authentic evidence-based to process the next counseling steps that assist students to make solutions on new self-motivation beliefs.

Iswinarti and Wahyuningsih (2018) also conducted a study that included interviews, observations, SSCT test, Self-Esteem Rating Scale (SERS), and Reality Therapy intervention. The results of this program were the increase of self-esteem with positive behaviors such as accepting of students' family situation, enhancing learning motivation, promoting students in expressing their needs to parents, being confidence in public, engaging relationship with new people, pursuing achievement goals, and being self-appreciation. The WDEP technique significantly helps students attain the recovery phase more quickly (Wubbolding, 2000; Corey, 1995; as cited in Iswinarti \& Wahyuningsih, 2018). Through this technique, the participants could be aware of their unreal hope as well as the discriminating behavior of their parents. They did not merely indicate that the parents loved the siblings more than the client. Hence, students no longer feel they are suffering due to the lack of appreciation by their family members. They also recognized that their ways were inadequate. They were committed to making a better change after recognizing their inner strengths (Mulawarman et al., 2017; Iswinarti \& Wahyuningsih, 2018; Sari et al., 2020).

According to Sari et al., (2020), Reality therapy and value judgement approaches have reduced the bullying behavior of vocational students. This study has some weak points, such as the participants who only carried out bullying were the subjects of the study, and seeing bullying based on visible behavior, especially, the authors have not yet found out the underlying motives that provoke bullying behavior. The findings still have certain limitations. However, the strengths of this study were that students were taught about evaluating the values, absorbing them, and then applying them in their daily lives during the WDEP process. Therefore, students began to develop the mutual respect, and bullying behaviors were diminished.

\section{Conclusion}

The findings of this research may have some useful implications for educators, school counselors, psychologists, researchers, social workers in promoting the feasible strategies to assist students solve their problems. In fact, Reality therapy has contributed much in the field of education in applying the core tenets of Reality therapy and Choice theory to help students improve their physical and spiritual health. Self-evaluation, personal responsibility, and planning for change to pursue achievement goals are the three common themes that were studied in the last 5 years as the strengths of Reality Therapy interventions. There is an increasing interest in using Reality therapy-based group counseling since group members appropriately support each other, and thus, these programs can reach to success. It is worthy of notice that the findings of these researches are limited due to the small sample size as well as the lack of follow-up assessment. Therefore, future researches may investigate the efficacy of applying Reality therapy in education with larger sample size. In addition, it is critical to have follow-up data from the subject or control groups to evaluate long-term outcomes since follow-up assessments are more effective to the conclusions.

16 Consortia Academia Publishing (A partner of Network of Professional Researchers and Educators) 


\section{References}

Çelik, Ç.B., \& Odaci, H. (2018). Psycho-educational group intervention based on reality therapy to cope with academic procrastination. Journal of Rational-Emotive \& Cognitive-Behavior Therapy, 36(3), 220-233. https://doi.org/10.1007/s10942-017-0283-1

Farnoodian, P. (2016). The effectiveness of group reality therapy on mental health and self-esteem of students. International Journal of Medical Research and Health Sciences, 5, 18-24.

Fereydouni, H., Omidi, A. \& Tamannaeifar, Sh. (2019). The effectiveness of choice theory education on happiness and self-esteem in university Students. Journal of Practice in Clinical Psychology, 7(3), 207-214. https://doi.org/10.32598/jpcp.7.3.207

Hajhosseini, M. (2017). Effectiveness of group counseling based on reality therapy on academic procrastination and behavioral self-regulation of students. International Journal of Behavioral Sciences, 10, 167-172.

Iswinarti, \& Wahyuningsih, Y. P. (2018). Group reality therapy to increase self-esteem in adolescents. https://doi.org/10.2991/ACPCH-17.2018.10

Jusoh, A. J. (2018). Choice theory and reality therapy in individual and group counseling in a Malaysian context. International Journal of Choice Theory and Reality Therapy, 37, 75-85.

Masoudi, S. (2016). Effect of reality therapy on achievement motivation and problem-solving skills in students.

Mason, C., \& Duba, J. (2009). Using reality therapy in schools: Its potential impact on the effectiveness of the ASCA national model. International Journal of Reality Therapy, 29(2), $5-12$.

Mulawarman, Sunawan, \& Amin, Z. (2018). The effectiveness of reality therapy for decreasing self-motivation problems of lower group students. https://doi.org/10.2991/ICEI-17.2018.63

Mabeus, D., \& Rowland, K. (2016). Reality therapy in a middle school setting: Altering a student's perception.

Nurjanah, A., Sanyata, S., \& Zatrahadi, M. (2020). The effectiveness of reality therapy in improving learning motivation and discipline. Jurnal Bimbingan Dan Konseling, 9(2), 87-91. https://doi.org/10.12928/psikopedagogia.v9i2.19470

Odacı, H., \& Çelik, Ç. (2017). Group counselling on college students' internet dependency and life satisfaction. Journal of Psychologists and Counsellors in Schools, 27(2), 239-250. https://doi.org/10.1017/jgc.2017.9

Sunawan, \& Junmei, X. (2016). An application model of reality therapy to develop effective achievement goals in tier three intervention. International Education Studies, 9(10), 16-29. https://doi.org/10.5539/ies.v9n10p16

Sari, P., Thahir, A., Utami, F. (2020). Reality counseling with value judgement techniques to reduce bullying behavior of vocational students. Psychology Research on Education and Social Sciences, 1(2), 83-89. https://doi.org/10.9734/BJESBS/2016/26093

Shafie, A. A. H. Bin, Kahar, N. F. B. A., Rahimi, M. K. A. Bin, \& Ahmad, R. Bin. (2019). The effectiveness of reality group counseling therapy in enhancing multiple intelligence among Malaysian students with the tendency of problematic internet use (PIU). International Journal of Academic Research in Business and Social Sciences, 9(6), 247-258. https://doi.org/10.6007/ijarbss/v9-i6/5944

Vahidiborji, G., Jadidi, M., \& Donyavi, R. (2017). The study of effectiveness of reality therapy on adjustment of female adolescent with anxiety. Psychol Clin Psychiatry 7(1), 1-4. https://doi.org/10.15406/jpcpy.2017.07.00414

Wubbolding, R. E., Casstevens, W. J., \& Fulkerson, M. H. (2017). Using the WDEP system of reality therapy to support person-centered treatment planning. Journal of Counseling \& Development, 95(4), 472-477. https://doi.org/10.1002/jcad.12162

Zare, F., \& Namdarpour, F. (2020). The effectiveness of choice theory training on the mental health of 
Au, P. A.

adolescent girls. International Archives of Health Sciences, 7(3), 131-136.

https://doi.org/10.4103/iahs.iahs_4_20

18 Consortia Academia Publishing (A partner of Network of Professional Researchers and Educators) 